ACTA UNIVERSITATIS LODZIENSIS

FOLIA LITTERARIA POLONICA 5(43) 2017

http://dx.doi.org/10.18778/1505-9057.43.06

Agnieszka Kampka*

\title{
Persuasive functions of photo galleries on information websites
}

The goal of this article is to answer the question whether photography, the visual online form of a media expression, can be a tool for shaping the opinions and attitudes of the reader. To answer it, one must consider whether a series of photographs constitutes a coherent message, thus whether treating a photo gallery as a single text and not a collection of independent images is justified. "The best photo of the week", "this is the world buzz", "you cannot miss this" - these slogans appear on websites and lead to galleries which have become a very popular form of journalism. Susan Sontag once wrote about the exceptional power of a photograph: "In teaching us a new visual code, photographs alter and enlarge our notions of what is worth looking at and what we have a right to observe. They are a grammar and, even more importantly, an ethics of seeing. Finally, the most grandiose result of the photographic enterprise is to give us the sense that we can hold the whole world in our heads-as an anthology of images"1. An online photo gallery seems to be a realisation of such an assumption: to show in a dozen or so images what life looked like in the past week. That is why it is worth checking to what extent the fulfilment of the idea is, at the same time, the act of providing a ready-made interpretation of the world.

\section{Online galleries}

Online news galleries - Helen Caple and John S. Knox ${ }^{2}$ used the term to define visual material which was created with the intention to be posted on the internet. It was created by a media information organisation, and the photographs are organised in collections based on certain assumptions, which leads to

* Ph.D. hab., e-mail: agnieszka_kampka@sggw.pl; Chair of Sociology, Faculty of Social Sciences, Warsaw University of Life Sciences.

${ }^{1}$ S. Sontag, "On Photography", Picador, New York 2001, p. 3.

${ }^{2}$ H. Caple, J.S. Knox, "Online news galleries, photojournalism and the photo essay", Visual Communication 2012, Issue 11, pp. 207-236. 
a certain goal. Caple and Knox analysed online photography galleries as a place where new genres of multimodal news delivery were being realized. They also showed how to study them by referring to storytelling. Online galleries may seem a paradise for photojournalists as they can use them to post many photographs of a given event, while in a traditional newspaper they usually have to limit themselves to just one image. In the former, they can show more, and involve the receiver more. Galleries are also very popular - they are the main element that people view on an information site. Pablo J. Boczkowski ${ }^{3}$ called newspaper archives a morgue, but today the possibility to use archived material on the internet offers new opportunities for commercialising them. Photographs which had previously been rejected can be used in online galleries, and now be a part of a new semiotic message.

Online galleries are a series of images. However, if one views them in a sequence, one must assume that they possess a rhetorically formed beginning, centre and ending, all adapted to the requirements of narration, which is the most common form of information sharing ${ }^{4}$. Therefore, a photo gallery has a specific rhetoric structure. Bo Bergstrom posited that a photograph can be evaluated in terms of its persuasiveness in regard to the extent it fulfils the assumed goal ${ }^{5}$. The analysis presented in this study was applied to Africa's top shots photo galleries, photographs posted on the BBC website in the news section devoted to Africa. The study material was posted in January 2017, and it consisted of 66 photographs. The rhetorical analysis answered the question: can a photo gallery presenting the last week's "top shots" collection be considered as a coherent message fulfilling specific persuasive intentions?

\section{Significance of visual journalism}

Visual journalism transmits information through images. Thus the reader can more quickly and efficiently understand the message and develop a strong emotional involvement with the content she/he takes in. Visual messages meet the needs of contemporary media receivers, who seek simple and short pieces of information. The act of viewing twelve slides is surely less time-consuming than delving into detailed analyses or reports (though they are increasingly often substituted with infographics).

\footnotetext{
${ }^{3}$ P.J. Boczkowski, "Digitizing the News: Innovation in Online Newspapers", MIT Press, Cambridge 2004, p. 59.

${ }^{4}$ H. Caple, J.S. Knox, op. cit., p. 208.

${ }^{5}$ B. Bergström, „Komunikacja wizualna”, transl. by J. Tarnawska, Wydawnictwo Naukowe PWN, Warsaw 2009, p. 161.
} 
A unique and surprising situation - that is what photojournalists usually want to present. According to Kazimierz Wolny-Zmorzyński: "In press photography it is not about the aesthetic capturing of reality, but rather showing the world the way it is" journalistic photography: authenticity, informativeness, iconicity (understood as a reference to iconographic models and the symbolic potential), composition, and the emotional load.

In the subject literature, one can find statements arguing that press photography does not need captions as it is identifiable through the use of iconic models (which, in fact, is the reason why photographs are so useful in the media as, at some level of presentation, they are understandable regardless of possible cultural differences; a viewer can identify what they present by referring to her/his existing knowledge and experience). It seems, however, that in order to offer a complete piece of information, an image must be accompanied by text ${ }^{7}$. Even though the informativeness of a photograph depends on the context and the caption, only a photograph has the power to transform the receiver of the text into a viewer giving her/him the opportunity to participate as an observer in the presented events ${ }^{8}$.

Photographs inspire and evoke emotions. They enable the message to be condensed, and encourage further reading and seeking information. The selection of the photographs is the main issue. When studying it, researchers sometimes use the notion of the value of a piece of news. characteristics or indicators of items of news; the existence of which explains why some events appear in the media while others do not. The main indicators include: destruction, violence/aggression, controversy, celebrities, something unexpected, emotions, quality of production and technical perfection, and sexuality/eroticism. Studies conducted on selected media have shown, in relation to visual messages, the value of such indicators as emotions, presence of celebrities, quality of production and technique, and showing something unexpected, while a controversial nature and sexuality had no significance for the studied editors ${ }^{10}$.

There is a predominant conviction that images are used as symbols which are to support the dominant discourse of the piece of news, that they are mainly simple thematic cues, straightforward symbolic markers, which enhance the narration of news, and co-create a larger ideological whole. Individual war photographs, for

\footnotetext{
${ }^{6} \mathrm{~K}$. Wolny-Zmorzyński, "Jak oceniać i wartościować fotografię dziennikarską", Zeszyty Prasoznawcze 2016, Vol. 59, Issue 2 (226), p. 329.

${ }^{7}$ W. Pisarek, „Nowa retoryka dziennikarska”, Towarzystwo Autorów i Wydawców Prac Naukowych Universitas, Cracow 2002, pp. 257-269.

${ }^{8}$ A. Smolińska, "O funkcjach fotografii prasowej (Kilka uwag na przykładzie magazynu popularnego)", Zeszyty Prasoznawcze 1972, Issue 4, p. 40.

${ }^{9}$ P. Rössler et al., "Selection and impact of press photography. An empirical study on the basis of photo news factors", Communications 2011, Issue 36, pp. 415-439.

${ }^{10} \mathrm{Ibid}$.
} 
example, may amplify the myth of war as an expression of patriotism and the strength of a country ${ }^{11}$. Images do not only work immediately and for a short time; they influence the collective imagination in the longer perspective ${ }^{12}$. Similarly to media information created socially, the grammar of an image, the visual grammar is constructed based on a culture. It always depends on the context, on the social sources of meaning available to the viewer at a given moment ${ }^{13}$.

Photographs published in the media frame reality focus attention, and present particular notions in a punchy and expressive manner. The frames in the case of photography can be understood as a point of view presented by the camera, a point of view which the viewer is also supposed to accept. Framing in the media consists of creating patterns of identifying and interpreting through selecting and emphasising certain elements while omitting others ${ }^{14}$. They propose specific definitions of a problem, specific interpretations, and moral evaluations ${ }^{15}$. As a notion, frames seem both indispensable and elusive. Usually unspoken and subconscious, they organise both the perception of journalists and their receivers. They are important in the process of constructing meaning. Frames have much in common with narration, as they too organise experiences, organise and categorise events by turning them into something that can be told. They offer the world a meaning ${ }^{16}$.

Visual framing is a common topic in media studies ${ }^{17}$. The visual media message operates as a teacher of values, ideology, and convictions. Images can be offered to viewers to impose a certain interpretation of the world, even if that was not the intention of their creators. Images create a realm of visions which we consider as something obvious ${ }^{18}$. Many receivers are not aware of the fact that reality is constructed socially through media images. They appear to be transparent reflections of reality, not interpretations. Journalists do not feel obliged to present various points of view using images, though in general they realise how important that is in verbal communication ${ }^{19}$.

${ }^{11}$ B. Zelizer, "Journalism through the Camera's Eye", in: “Journalism: Critical Issues", S. Allan (ed.), Open University Press, Maidenhead 2005, p. 174.

${ }^{12}$ K. Andén-Papadopoulos, "The Abu Ghraib torture photographs: News frames, visual culture, and the power of images", Journalism 2008, Issue 9, p. 6.

${ }^{13}$ M. Schudson, "The sociology of news production", Media Culture Society 1989, Issue 11, pp. 263-282.

${ }^{14}$ T. Gitlin, "The Whole World Is Watching: Mass Media in the Making and Unmaking of the New Left", University of California, Berkeley 1980, p. 28.

${ }^{15}$ R.M. Entman, "Projections of Power: Framing News, Public Opinion, and US Foreign Policy", University of Chicago Press, Chicago 2004, p. 6 and the following.

${ }^{16}$ W.A. Gamson et al. "Media Images and the Social Construction of Reality", Annual Review of Sociology 1992, Issue 18, p. 385.

${ }^{17}$ L. Rodriguez, D.V. Dimitrova, "The levels of visual framing”, Journal of Visual Literacy 2011, Vol. 30, Issue 1, pp. 48-65.

18 W.A. Gamson et al., op. cit., p. 375.

${ }^{19}$ Ibid. 


\section{The object and assumptions of the analysis}

The rhetorical analysis of visual messages combines both elements of multimodal discourse analysis (as it considers all communication channels) and the approach typical for social semiotics, as the researcher's attention is focussed on everything that functions as a sign, which can be considered a symbol through which meaning is created.

The first research question applies to the coherence of the photographs collected in a gallery. Online galleries are often used for illustrating a specific event or they apply to a single person. The analysed case consisted of a rather random, it seems, collection of photographs related to one another through the continent on which they were taken. They came from 17 countries (out of a total of 54 African countries), which itself indicated a partial view of life in Africa presented in the gallery. The coherence of the message was achieved at several levels. First of all - regarding the technical layer. The photographs were posted on the website one under another, in an easily scrollable layout, which is today probably the most popular form of browsing websites. Secondly, the coherence was ensured by texts or captions. And finally, also the visual layer of the photographs formed a certain whole.

In eight cases, one event was illustrated with several shots. Those included both individual events (presidential inauguration, fire-fighting efforts, demonstrations and their dispersion) and events stretched over time (the celebrations of the Orthodox holiday of Epiphany), as well as those which consisted of individual events which occurred in various locations (football games and photographs of supporters from various cities).

Verbal devices were often used to link the photographs. Verbal interrelatedness within the gallery applied to 40 photographs. In 28 cases, the connections between the photographs were achieved through visual means. In 19 cases, the photographs shared themes (e.g. dance, street parades, New Year's celebrations). Only 11 photographs were not connected with the neighbouring ones in any way.

\section{Verbal markers of coherence}

At the caption layer, one can indicate several methods of connecting the photographs: 1) through conjunctions and prepositions, 2) through temporal identification, 3) through indicating cause and effect relationships. An ellipsis concluding or opening a caption was another marker of a relationship between them. 
(1) On Wednesday, women pose for a selfie during the annual Timkat epiphany celebration in the Ethiopian city of Gondar... (photo 30), It is an Orthodox Christian festival marking the baptism of Jesus in the River Jordan... (photo 31) The next day, worshippers jump into the Fasilides Bath - the waters of which are blessed by a priest as part of a ceremony... (photo 32).

Conjunctions and prepositions usually appeared in the case of photographs of the actual event:

(2) On New Year's Eve, clowns perform on stage at the One Lagos fiesta in Nigeria's commercial capital Lagos (photo 1). Dancers and singers $\mathbf{a l s o}^{\mathbf{2 0}}$ perform as part of the night's entertainment (photo 2).

(3) On Saturday, a young supporter of new Ghana President Nana Akufo-Addo during his inauguration in Accra... (photo 13) At the same event, a drummer entertains the presidential well-wishers... (photo 14) While these men blows their horns for the new president. (photo 15).

Usually, the photographs were connected using temporal identification:

(4) Young ballet dancers practise their moves in Kibera slum in Kenya's capital, Nairobi, on Wednesday. (photo 26) On the same day, children use plastic sacks to slide down a slope after snowfall on the outskirts of Medea in Algeria. (photo 27).

(5) On Tuesday, a 19 year-old migrant from Gabon is found hiding in a suitcase during a border check between Morocco and the Spanish enclave of Ceuta (photo 10). An aircraft drops water on a wildfire raging in the Helderberg mountains near Cape Town in South Africa on Wednesday (photo 11).

(6) On Tuesday, the daughter of slain Burundian Water Minister Emmanuel Niyonkuru blesses her father's grave during his funeral in Bujumbura. (photo 24) On Wednesday, an Algerian police lieutenant kneels as she watches a homeless girl eat during "Winter Soup", a charity drive by police to feed homeless people, in Algiers. (photo 25).

However, the inclusion of the days of the week did not have to form a chronological whole as after the Wednesday photograph there might have appeared a... Monday image: (8) "On Monday, children displaced by fighting in southern Kaduna, Nigeria, stand in front of a house where they had sought refuge". (photo 26).

The presented events were less often connected using the cause and effect relationship:

${ }^{20}$ All instances of emphasis in the captions were introduced by me. 
(9) Neighbouring Ivory Coast was rocked on Saturday by a mutiny with these soldiers out on the streets of Bouake, the second largest city, demanding better treatment... (photo 16) News of the mutiny disrupted the flow of traffic into Bouake, meaning these passengers had time on their hands. (photo 17).

(10) On Sunday, members of the \#BringBackOurGirls campaign rally in Nigeria's capital Abuja to mark 1,000 days since more than 200 girls were kidnapped from their school in Chibok... (photo 18) All did not go well for the activists as they later saw these riot-police officers charge at them to disrupt their rally. (photo 20).

The final example is also interesting due to the fact that the photographs and the caption somewhat foreshadowed what else was happening but which was not presented in the gallery.

The captions "glued together" photographs which are not associated in any way:

(11) A participant in a street parade in Cape Town shows serious attitude (photo 5) ...while another fancy-dresser shows his cheeky side at a traditional festival in Winneba, Ghana (photo 6).

Each of the photographs came from a different country. It was not even clear whether they were taken on the same day. What connected them, and what was indicated in the caption, was supposed to be, on the one hand, the contrast: serious/cheerful, and, on the other, the similarity of the two situations: both showed a street party.

(12) A security guard on patrol during the launch of the first batch of Standard Gauge Railway freight locomotives at the port in Mombasa, Kenya on Wednesday. (photo 21). Also on Wednesday, South Sudanese wheelchair basketball players train in the capital, Juba. (photo 22) While Tunisian boys throw stones towards a police station in a town on the border with Libya where locals are angry at a ban on crossborder trade. (photo 23).

The aim of that device was to offer the viewer a somewhat bird's-eye view of Africa, and see various places and events simultaneously. Moreover, such a method of presentation applied not only to events happening at the same time:

(13) A group of pantsula dancers pose in Johannesburg's Alexandra township on Wednesday. This kind of street dancing began in townships during apartheid and is often a form of social commentary... (photo 62). Three days earlier, followers of South Africa's Shembe church, a loose combination of Zulu culture and Old Testament Christianity, attend a gathering in eBuhleni. Some of them are wearing fake pelts designed by conservationists in an effort to save leopards. (photo 63). 
In that case, the basis for coherence in the photographs was a theme: dance. The same applied to other photographs connected through a common theme, but which additionally jointly formed a visual narrative:

(14) Boys warm up to play football on a beach in the slum township of West Point in Liberia's capital, Monrovia, on Saturday... (photo 37) The next day, another group play a game on the streets in central Monrovia where there is a shortage of football pitches. (photo 38).

That example leads to visual methods of connecting photographs.

\section{Visual markers of coherence}

Visual markers included several techniques: 1) similarity or repetition of composition, 2) similarity of colour scheme, 3) similarity or repetition of motifs.

First of all, in the case of composition, it can be the case that neighbouring photographs present a similarly divided space, a similar perspective. Secondly, consecutive photographs force the viewer to view them the same way, e.g. the first one was a photograph of a woman in fancy headgear with a bunch of feathers; the following was a photograph of boys warming up before a game, but their arrangement was similar to the arrangement of the previously viewed feathers. Another example: a panorama of a number of mounted soldiers in white kufiyas, while the following was a photograph of a dancer during a street parade, and the black-and-white pattern on his spinning attire was reminiscent of the arrangement of the people in the previous image.

Colour is another visual connector. It was most visible in the connected photographs of camels strolling through salt (white) and of a snowman in a snowcovered (white) street.

The photographs were also connected through their motifs. The first photograph presented two girls in black hijabs smiling. The other was a photograph of a group of smiling girls in white hijabs. A photograph of men sitting on a tank was preceded by a photograph of an armed patrol. The photograph presented a group of men celebrating a won game and tossing one of their members into the air; his legs are right in the centre of the photograph. In the following photograph: a group of protesters, and in the centre the arms of one of them.

The similarity or repetition of certain forms or elements was not always obvious. For example, two photographs from Ethiopia from a celebration of a religious holiday: in one of them, there was a crowd surrounding a pool full of people. In the foreground, there was a man jumping into the water with his arms and legs 
spread. His figure resembles the cross which was present in the centre of the following photograph. Another example: in a photograph of female dancers, in the background, there is a shaft of blue and violet laser light, the shape of which resembles a triangle. In the following photograph, there were pyramids and laser light shooting from between them drawing in the sky shapes similar to those from the previous one.

The similarity of gestures was another visual connector. In that case, the most distinct was the set where in the first photograph, there were two men lying at the gun of a tank and waving to the viewer, and, in the other, two girls reaching out to take a selfie. Those were not the same gestures, yet close enough for the viewer to identify a common pattern in them.

\section{Narrativeness}

Even though the narrative nature of the whole seems obvious in the case of online galleries which apply to a single event, the need for it in the analysed case was not apparent. The previously-described procedures used for building the coherence of the message are also the means leading to the creation of a story about Africa. One could talk about narrativeness at the level of a single photograph, a set of several images, as well as at the level of the whole gallery.

Therefore, let us look at the events and figures depicted by the photographs. In the analysis, I identified several thematic categories: sports, politics, religion, everyday life, entertainment, and protests. The largest group of photographs depicted everyday life (17), sports (15), and entertainment (13).

Everyday life consisted of scenes of regular activities not related to any special events. That included doing shopping in the market or putting out fires by firefighters. A woman sitting on the beach, a man quenching his thirst with coconut milk, people waiting at the border, and children standing around in front of a house. However, some of the photographs classified as everyday life were, as indicated in the captions, political in nature as well. The people waiting at the Gambia border feared violence after the election and were fleeing to Senegal. The children standing around in front of a house were refugees from a warinflicted area.

The sports category included two subcategories: people practising sports and spectators. In the case of the former, it applied mainly to football. The photographs included: a player lying on the pitch exercising, a basketball team in wheelchairs gathered in a circle before a training session, a children's team starting their training session, a group of men playing football in the street, and, finally, kite-surfers. The spectators' group was more diverse. They mainly included 
supporters watching championships, six photographs were portraits of supporters in costumes or with painted faces, one - a group of supporters in the stands with flags and flares. One photograph was particularly interesting. It included workers working on a road (construction?) and watching footballers running while training. Another interesting photograph was a photograph of a large group of men and boys staring at a screen located outside of the shot which displayed a match. The football championships held within the analysed period explain the large number of thus-themed photographs. However, what was striking was the lack of photographs of the main characters, i.e. the footballers.

In fact, the same applied to the photographs classified as depicting politics. Those presented two types of events: either ceremonies (a presidential inauguration, a funeral, a presidential farewell), or demonstrations and protests. It is noteworthy that the only politician who appeared in the photographs (and was identified with a caption) was the out-going president of Gambia. None of the photographs included the new president of Ghana. The events were presented from the perspective of the ordinary people who participated in them.

The manner of presenting religion was also interesting. The gallery included representations of various religions one can encounter in Africa, e.g. the picturesque Shembe followers in line with the stereotypical visions of Africa, as well as followers of Islam and Christianity. The last two religions were presented through images of young people: Islam - through the image of a group of joyful young girls meeting in a stadium to prove that the hijab is not a means of oppression. Order is maintained by two policewomen - young, smiling, and also in hijabs. The photographs presenting the Christian celebrations of Epiphany included young people - girls taking a selfie, and boys fooling around in front of the photographer.

Usually, the characters in the photographs did not establish any contact with the viewer (through the contact with the photographer). In the case of only ten photographs, the subjects were posed. Why is that important? Eye contact with the viewer may evoke stronger emotions. But most of all, a person looking at the viewer is fully aware of the fact that she/he will be viewed, thus somewhat making a statement, and becoming a co-creator of the photograph. Naturally, it is the author that decides about the form of a photograph, and the editor about its utilisation, however, if one views that as storytelling - a person consciously posing for a photograph makes a statement offering an "independent voice" in the photograph.

Who were the people presented in the photographs? It is noteworthy that the majority of them were not presented while at work. The main characters mainly included persons having fun. Only a few photographs depicted people at work: firefighters putting out a fire, a policewoman feeding the homeless, policemen running towards demonstrators, women selling produce and clothes at a market, and men selling coconuts. Workers at a construction site stop their work to look 
at footballers training. Dancers perform their work, but it is associated with entertainment. The majority of those working were in uniform: firefighters, an army patrol, railway guards, and Muslim policewomen.

\section{Conclusions}

Do the analysed photographs fulfil the specified persuasive goal? Do they form a coherent image of Africa? Let me return to the criteria of attractiveness of press photography. Destruction, violence, controversy, celebrities, something unexpected, emotions, quality of production and technical perfection, and sexuality - actually only a few of the photographs met some of the criteria. One could identify elements of violence (riots, armed soldiers and police officers), and emotions - mostly positive, related to enjoying oneself, street festivals, supporting sporting events, and joy in winning. It would be difficult, though, to conclude that the photographs included in the gallery were of a news piece nature. As I have mentioned before even if they were related to a significant event, e.g. the presidential inauguration, they did not present the main figures. So what is their value? How could they form an attractive persuasive message? Could one talk about the frames used by editors in the case of the selected photographs of the last week?

The presented analyses indicate that the studied galleries could be considered as a coherent complete message. The indicated verbal and visual connectors suggest the purposefulness of the procedures aimed at enhancing the narrative nature of the whole. Therefore, the objective was not to present the best, the most interesting, or the most popular photographs, but to construct a specific message. Secondly, the themes of the photographs, the presentation of the events, and the selection of the subjects all indicated a purposeful choices made by the editors.

On the basis of the analysis, two frames could be defined: Africa is having fun and Africa needs order. The Africa is having fun frame was visible in the predominance of photographs depicting festivals, holidays, and sports fans. They presented elaborate costumes, enthusiasm, and joy. The Africa needs order frame was suggested by a similarly large number of photographs which included state functionaries, often with guns, as well as by the number of photographs documenting demonstrations, strikes, and protests. One should note, though, that both frames could be read differently, depending on the knowledge and attitude of the receiver. Africa is having fun could mean that a) the people who live in Africa are joyful and can appreciate life, or b) the people who live in Africa are lazy and prefer to have fun than work. Africa needs order, i.e. a) African countries need help from outside because they cannot cope on their own with the 
protests and crime, b) African people cope well with maintaining social order, and the protests only prove their civil self-awareness.

In summary, online photo galleries certainly constitute a persuasive form of journalistic expression. They can constitute a tool for shaping the attitudes and views of their receivers. Their rhetorical potential is particularly visible when one considers not only individual instances, but rather series referring to the same theme.

\section{Bibliography}

Andén-Papadopoulos K., "The Abu Ghraib torture photographs: News frames, visual culture, and the power of images", Journalism 2008, Issue 9, pp. 5-30.

Bergström B., „Komunikacja wizualna”, transl. by J. Tarnawska, Wydawnictwo Naukowe PWN, Warsaw 2009.

Boczkowski P.J., "Digitizing the News: Innovation in Online Newspapers", MIT Press, Cambridge 2004.

Caple H., Knox J.S., "Online news galleries, photojournalism and the photo essay”, Visual Communication 2012, Issue 11, pp. 207-236.

Entman R.M., "Projections of Power: Framing News, Public Opinion, and US Foreign Policy", University of Chicago Press, Chicago 2004.

Gamson W.A. et al. "Media Images and the Social Construction of Reality", Annual Review of Sociology 1992, Issue 18, pp. 373-393.

Gitlin T., "The Whole World Is Watching: Mass Media in the Making and Unmaking of the New Left", University of California, Berkeley 1980.

Pisarek W., „Nowa retoryka dziennikarska”, Towarzystwo Autorów i Wydawców Prac Naukowych Universitas, Cracow 2002, pp. 257-269.

Rodriguez L., Dimitrova D.V., “The levels of visual framing”, Journal of Visual Literacy 2011, Vol. 30, Issue 1, pp. 48-65.

Rössler P. et al., "Selection and impact of press photography. An empirical study on the basis of photo news factors", Communications 2011, Issue 36, pp. 415-439.

Schudson M., "The sociology of news production", Media Culture Society 1989, Issue 11, pp. 263-282.

Smolińska A., "O funkcjach fotografii prasowej (Kilka uwag na przykładzie magazynu popularnego)", Zeszyty Prasoznawcze 1972, Issue 4, pp. 33-40.

Sontag S., "On Photography”, Picador, New York 2001.

Wolny-Zmorzyński K., "Jak oceniać i wartościować fotografię dziennikarską", Zeszyty Prasoznawcze 2016, Vol. 59, Issue 2 (226), pp. 326-334.

Zelizer B., "Journalism through the Camera's Eye", in: "Journalism: Critical Issues", S. Allan (ed.), Open University Press, Maidenhead 2005, pp. 167-176.

\section{Internet sources}

Africa's top shots: 30 December 2016-6 January 2017, http:/www.bbc.com/news/world-africa-38518088 [accessed on: 04.2017]. 
Africa's top shots: 7-13 January 2017, http://www.bbc.com/news/world-africa-38599079 [accessed on: 04.2017].

Africa's top shots: 13-19 January 2017, http://www.bbc.com/news/world-africa-38684879 [accessed on: 04.2017].

Africa's top shots: 20-26 January 2017, http://www.bbc.com/news/world-africa-38760872 [accessed on: 04.2017].

Africa's top shots: 27 January-2 February 2017, http://www.bbc.com/news/world-africa-38847656 [accessed on: 04.2017].

Agnieszka Kampka

Persuasive functions of photo galleries on information websites

(Summary)

The article presents a rhetorical analysis of online galleries. The author argues that the selection of photographs presented in a gallery serves the purpose of fulfilling a persuasive goal. That is proved by, as indicated in the analysis, the verbal and visual markers of coherence, and the narrativeness visible at the level of individual photographs, groups of photographs, and the entire gallery.

Keywords: online gallery, rhetorical analysis, persuasion, coherence markers, narrativeness. 